\title{
PREDISPOSING FACTORS AND TREATMENT OUTCOME OF OTOMYCOSIS
}

\author{
Arifullah $^{1}$, Syed Zafar Hassan ${ }^{2}$, Israr-Ud-Din ${ }^{3}$ \\ 1. Town Teaching Hospital \\ 2. District Hospital Kohat \\ 3. Khyber Teaching Hospital
}

\begin{abstract}
OBJECTIVES:

The aim of this study was to determine the predisposing factors and treatment outcomes of otomycosis.

METHODS:

This was an observational study conducted from July 2008 to August 2012 at ENT department of Khyber Teaching Hospital, Peshawar. Total of 110 patients of all age and both sexes we re selected from OPD for the study, using convenient sampling. The predisposing factors and treatment outcome of otomycosis were observed. Results were recorded in percentages.
\end{abstract}

\section{RESULTS:}

In our study we documented 110 patients having otomycosis. There wer e 57.3\% (63/110) males and $42.7 \%$ (47/110) females. Patients ranged from 21 to 40 years were more affected. Mean follow up time was 2 years. The most common predisposing factors were swimming in $49.1 \%(54 / 110)$ patients followed by topical antibiotic drops, cerumen, immune-compromised status and hearing aid use. The most common presenting symptom was otalgia and itching ear in almost every patient 100\% (110/110), followed by hearing loss and ear discharge. In our study $1 \%$ clotrimazole drops or lotion was appied to all patients after cleaning the fungus debris and cleansing the ear with acetic acid. The treatment outcome was resolution in $57.3 \%$, residual $24.5 \%$ and recurrence $12.7 \% .5 .5 \%$ of patients did not come for follow up. The complications were TM perforat ion in $13.6 \%$ patients, serous otitis media in $3.6 \%$ and external auditory canal osteitis in $0.9 \%$.

\section{CONCLUSION:}

Otomycosisis usually resolves with local toilet of ear and instillation of antifungal agents, however eradication of disease is difficult in presence of a mastoid cavity and immune-compromised patients.

\section{KEY WORDS:}

Otomycosis

\section{INTRODUCTION}

Otomycosis is superficial fungal infection of outer ear canal ${ }^{1}$.Aspergillus is the most

Correspondence: Dr. Arifullah Contact:0302-5563597 Email: drmrf@hotmail.com https://doi.org/10.37762/jgmds.2-2.53
Town Teaching Hospital common fungi $(90 \%)$ followed by candida and other fungal species. It is unclear that the fungi are the true infective agents or mere colonization species not invading the tissue. The prevalence rate is about $10 \%$ of those patient $s$ having signs and symptoms of otitis externa ${ }^{3}$.The incidence of otomycosis is more common tropical/subtropical countries (also called Singapore ear) ${ }^{4}$. Various predisposing factors include a hot and humid climates, poor local hygiene and swimming or aquatic sports persons, presence of cerumen, instrumentation of the ear, increased use of topical antibiotics/steroid preparations, immune-compromised host, open cavity mastoidectomy and hearing aids users with occlusive ear mold $^{5,6}$. Clinically the infection may be either subacute or acute, characterized by inflammation, pruritus, scaling and severe discomfort. The most characteristic finding is the presence of greyish white thick debris (known as "Wet blotting paper") in external ear canal ${ }^{7}$.Swabs from infected ears should be examined for both bacteriology and mycology. 
Epithelial debris placed in $10 \%$ potassium hydroxide should reveal the presence of hyphae and, in some instances, the fruiting structures of the a etiological agent ${ }^{8}$.Treatment recommendations have included local debridement, ear cleaning with dilute aluminum acetate solution combined with acetic acid, application of local antifungal agents and discontinuation of topical antibiotics while systemic antifungal agents are used immmune compromised patients. Most of the cases settled in one week and in resistant cases the treatment is continued for three weeks.

Sometimes otomycosis presents as a challenging disease for its long -term treatment and may result in resolution, residual or recurren t disease ${ }^{10}$.Complications of otomycosis included serous otitis media, TM perforation and osteitis of external auditory canal ${ }^{11}$. We conducted this study with the aim to determine the frequency, common presenting symptoms, predisposing factors and treatment outcome.

\section{METHODOLOGY}

It was observational study conducted from July 2008 to August 2012(four years duration) in ENT Department, Khyber Teaching Hospital, Peshawar. Patients were prospectively recruited via non-probability convenience sampling. It composedof 110 patients of both sexes and all age groups with documented diagnosis of otomycosis.

Data was collected regarding predisposing factors, common symptoms, treatment outcomes and follow up duration. Statistical analysis was carried out. The diagnosis of otomycosis was made on the basis of the recognizable and characteristic appearance of fungal debris and fruiting bodies under microscopy. Cultures were not routinely obtained because there was generally a rapid response to treatment in most of the cases. The treatments offered to most of patients in the form of Clotrimazole 1\% lotion or cream(impregnated gauze) after cleaning the canalwith dilute aluminum acetate solution combined with acetic acid. Most of the cases settled in one week. The treatment was continued for three weeks in resistant cases.

After approval from the hospital ethical committee, all patients who fulfilled the inclusion and exclusion criteria were included in the study. Sampling technique was consecutive non -probability sampling and all the patients of all ages and of either gender were included in the study and those patients having earache due to acute otitis media, malignant otitis externa I, furunculosis, otitis external and referred otalgia were excluded from the study.

Successful treatment outcome was defined as 1) Resolution of all evidence of fungal infection on physical examination, 2) Residual disease that failed to respond to our initial choice of treatment and 3) Recurrent disease that occurred in patients who had resol ution of disease after initial treatment.

\section{RESULTS}

In our study we documented 110 patients having otomycosis. There were $63 / 110(57.3 \%)$ males and $47 / 110(42.7 \%)$ females. Patients ranged from 21 to 40 years were more affected 61/110 $(55.5 \%)$ as shown in table 1.

In our study the most common predisposing factor was swimming49.1\% (54/110) followed bytopical antibiotic drops $19.1 \%(21 / 110)$, cerumen (17/110), immune -compromised status $10 \%$ (11/110) and hearing aid use 4.5\% (5/110)as shown in table 2 . In this stu dy the most common presenting symptom was otalgia and itching ear in almost every patient $100 \%$ (110/110), followed by hearing loss $46.4 \%(51 / 110)$ and discharging ear $19.1 \%(21 / 110)$ as shown in table 3. 
In our study $1 \%$ clotrimazole drops/cream was applied fter removing the fungus debris and cleansing the ear with acetic acid. The treatment was continued for $1-8$ weeks. The outcome was resolution in $57.3 \%(63 / 110)$, residual $24.5 \%$ (27/110) and recurrence $12.7 \%$ (14/110).Six patients $(5.5 \%)$ did not come for follow up as shown in table 4.

In our study only $17.2 \%$ (19/110) patients' developed complications included TM perforation in $13.6 \%$ (15/110) patients' serous otitis media in 3.6/110\% (4/110) patients (and external auditory canal osteitis in $0.9 \%(1 / 110)$ patients as shown in table 5.

Table 1: Demographic features

\begin{tabular}{|l|l|l|}
\hline Sex and age of patients & Number of patients & Percentages \\
\hline Gender Male & $63 / 110$ & $57.3 \%$ \\
Female & $47 / 110$ & $42.7 \%$ \\
\hline Age of patients $1-20$ years & $34 / 110$ & \\
21-40 years & $61 / 110$ & $30.9 \%$ \\
More than 40 years & $15 / 110$ & $55.5 \%$ \\
\hline
\end{tabular}

Table 2: Predisposing factors

\begin{tabular}{|l|l|l|}
\hline Predisposing factors & Number of patients & Percentages \\
\hline Swimming & $49 / 110$ & $44.5 \%$ \\
\hline Antibiotics ear drops & $21 / 110$ & $19.1 \%$ \\
\hline Cerumen & $17 / 110$ & $15.5 \%$ \\
\hline Immunocompromised & $11 / 110$ & $10 \%$ \\
\hline Mastoidectomy cavity & $7 / 110$ & $6.4 \%$ \\
\hline Hearing aids & $5 / 110$ & $4.5 \%$ \\
\hline
\end{tabular}

Table 3: Clinical features

\begin{tabular}{|ll|l|l|}
\hline Clinical features & Number of patients & Percentages \\
\hline Symptoms & Pain in ear & $110 / 110$ & $100 \%$ \\
& Itching ear & $110 / 110$ & $100 \%$ \\
hearing & Decreased & $51 / 110$ & $46.4 \%$ \\
& & $21 / 110$ & $19.1 \%$ \\
\hline Examination findings & Discharging ear & & \\
& Fungal debris & $110 / 110$ & $100 \%$ \\
& Edematous EAM & $52 / 110$ & $47.3 \%$ \\
& Cerumen & $17 / 110$ & $15.5 \%$ \\
& TM perforation & $15 / 110$ & $13.7 \%$ \\
& Granulation & $9 / 110$ & $8.2 \%$ \\
\hline
\end{tabular}

Table 4: Follow up for 2 years

\begin{tabular}{|l|l|l|}
\hline Treatment outcome & Number of patients & Percentages \\
\hline Resolution & $63 / 110$ & $57.3 \%$ \\
\hline Residual & $27 / 110$ & $24.5 \%$ \\
\hline Recurrence & $14 / 110$ & $12.7 \%$ \\
\hline No follow up & $6 / 110$ & $5.5 \%$ \\
\hline
\end{tabular}


Table 5: Complications

\begin{tabular}{|l|l|l|}
\hline Complications & Number of patients & Percentages \\
\hline TM perforation & $15 / 110$ & $13.6 \%$ \\
\hline Serous otitis media & $4 / 110$ & $3.6 \%$ \\
\hline Osteitis of EAM & $1 / 110$ & $0.9 \%$ \\
\hline
\end{tabular}

\section{DISCUSSION}

Otomycosis is a superficial mycotic infection of the outer ear canal frequently encountered in a general otolaryngology clinic setting particularly in summer. The disease com monly occurs in adult males. In our study the disease was more common in male $(57.3 \%)$ as compared to female and the common age group was $21-40$ years about $55.5 \%$. a study conducted in Iran, otomycosis was most prevalent at the age of 20-40 years with highest incidence of infection in summer. ${ }^{12}$

The most common predisposing factors of otomycosis are swimming, cerumen, immunecompromised status, topical antibiotic drops, mastoid cavities and hearing aid use. In our study

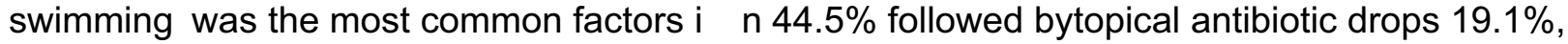
cerumen $15.5 \%$, immune compromised status $10 \%$, mastoid cavities $6.4 \%$ and hearing aid use $4.5 \%$. While in Indian study the predisposing factors were instillation of coconut oil $(42 \%)$, use of topical antibiotic eardrops (20\%) and compulsive cleaning of external ear with hard objects (32\% $)^{\beta}$. The otomycosis is usually unilateral and characterized by inflammatory pruritis, scalingotalgia, and the presence of fungal debris and inflammation of external auditory canal. In our study the most common presenting symptom was otalgia and it chin gin $100 \%$ patients followed by hearing loss $46.4 \%$ and discharging ear $19.1 \%$.Another study conducted in our country the most common presenting symptom was hearing loss $(77.7 \%)$ fol lowed by pruritus $(68.8 \%)$ and otalgia (40\%), fungal debris in the ear, scabs and inflammation of the external auditory meatus. ${ }^{14}$

The treatment of otomycosis consists of removal of fungal debris and topical antifungal. Clotrimazole for about two months isusually used with good efficacy. In our study clotrimazole after removal of fungal debris, was continued for 78 weeks. The outcome of the treatment was resolution in $57.3 \%$, residual $24.5 \%$ and recurrence $12.7 \% .5 .5 \%$ patients did not come for follow up. Andher study conducted in our countrythe efficacy of clotrimazole in treatment of otomycosis was observed in $89(94.12 \%) .{ }^{15}$ In Nigerian study the treatment failures were minimal, including recurrence $(2.6 \%)$, acute otitis external $(1.3 \%)$ and blocking of ear by therapeutic agent $(2.6 \%) .{ }^{16}$

Otomycosis may develop complications like TM perforation, serous otitis media and external auditory canal osteitis. In our study only $17.2 \%$ patients' developed complications included TM perforation $13.6 \%$, serous otitis media $3.6 \%$ and external auditory canal osteitis $0.9 \%$.In Australian study the perforations were observed after the fungal debris had been removed from the external ear canal using a microscope. ${ }^{17}$

\section{CONCLUSIONS}

Otomycosisis commonly presented with otalgia, pruritus, decreased hearing \& otorrhoea.

The disease usually resolves with local toilet of ear and instillation of antifungal agents.

Eradication of disease is difficult in presence of a mastoid cavity and immune-compromised status. 


\section{REFERENCES}

1. Miller-Keane Encyclopedia and Dictionary of Medicine, Nursing, and Allied.

2. Mahmoudabadi AZ. Mycological Studies in 15 cases of otomycosis. Pak J Med Sci. 2006;22(4):486-488.

3. Pradhan B, Tuladhar NR, Amatya RM. Prevalence of otomycosis in outpatient department of otolyryngology in tribhuvan university teaching Hospital, Kathmandu, Nepal. Ann OtolRhinolLaryngol. 2003;112(4):384-387.

4. Satish H et al; A Clinical Study of Otomycosis. IOSR Journal of Dental and Medical Sciences. 2013 May: 5(2):2279-0861.

5. Ford ES, Mokdad AH, Giles WH. Geographic variation in the prevalence of obesity, diabetes, and obesity related behaviours. Obes Res. 2005;13(1):118-122.

6. Jackman A, Ward R, April M, Bent J. Topical antibiotic induced otomycosis. Int J PediatrOtorhinolaryngol. 2005;69(6):857-860.

7. Kujundzic M, Braut T, Manestar D et al ; Water related otitis externa. CollAntropol. 2012 Sep;36(3):893 7.

8. Latha R, Sasikala R, Muruganandam N ; Chronic otomycosis due to malassezia spp. J Glob Infect Dis. 2010 May;2(2):189-90.

9. Vennewald I, Klemm E; Otomycosis: Diagnosis and treatment. ClinDermatol. 2010 Mar 4;28(2):202-11.

10. Ho T, Vrabec JT, Yoo D, et al; Otomycosis: clinical features and treatment implications. Otolaryngol Head Neck Surg. 2006 Nov;135(5):787-91.

11. Abou-Halawa AS, Khan MA, Alrobaee AA, et al ; Otomycosis with Perforated Tympanic Membrane: Self medication with Topical Antifungal Solution versus Medicated Ear Wick. Int J Health Sci (Qassim). 2012 Jan;6(1):73-7.

12. Gharaghani M 1, Sei fiZ, ZareiMahmoudabadiA.Otomycosis in iran: a rev iew.Mycopathologia. 2015 Jun;179(5-6):415-24.

13. Prasad SC, Kotigadde S, Shekhar M, et al. Primary otomycosis in the Indian subcontinent: predisposing factors, microbiology, and classification. Int J Microbiol. 2014;2014:636493.

14. Anwar K, Gohar MS. Otomycosis; clinical features, predisposing factors and treatment implications. Pak J Med Sci. 2014 May;30(3):564-7.

15. Khan F, Muhammad R, Rehman F, lqbal J, , Ullah G. Efficacy of topical clotrimazole in treatment of otomycosis. J Ayub Med CollAbbottabad. 2013 Jan-Jun;25(1-2):78-80.

16. Ologe FE1, Nwabuisi C. Treatment outcome of otomycosis in llorin, Nigeria. West Afr J Med. 2002 Jan Mar;21(1):34-6.

17. Hurst WB. Outcome of 22 cases of perforated tympanic membrane caused by otomycosis. J Laryngol Otol. 2001 Nov;115(11):879-80.

\section{(c) (1) (9)}

LICENSE: JGMDS publishes its articles under a Creative Commons Attribution Non-Commercial Share-Alike license (CC-BY-NC-SA 4.0). COPYRIGHTS: Authors retain the rights without any restrictions to freely download, print, share and disseminate the article for any lawful purpose. It includes scholarly networks such as Research Gate, Google Scholar, LinkedIn, Academia.edu, Twitter, and other academic or professional networking sites. 